\title{
TABLE BOOKING AND RESTAURANT MANAGEMENT SYSTEM USING ANDROID APPLICATION(OPSS)
}

\author{
B. Naveen Kumar, B. Sai Varun \\ UG Student, Dept. Of Computer Science, \\ Sathyabama University, Chennai, India. \\ Dr. Sarvanan. M \\ Assistant Professor, Dept. Of Computer Science, \\ Sathyabama University, Chennai, India.
}

\begin{abstract}
The ulterior motive of this android application is to manage everything correlated to managing a restaurant and tables in a restaurant. The regular restaurant service is typically laid back: Waiters should associate with customers straightly before dealing with their requests.

Nonetheless, a great system should always be focused on customers which should expeditiously perceive consumer charisma, front- runner cuisines. This application gives users the advantages of active ordering as well as hold their accessible table. This system is involved in the use of three applications combine with each other, and involved the use of five modules that are table reservation with food ordering at the same time, order delivery system, take away and get in touch with us. This application also holds the data for the admin (manager of particular restaurant) which includes payments, No. of orders and also the admin can dynamically change the menu accordingly with prices with blocking the table booking option for the users subjected to the availability of table. Customers and management can have the data using analytics. This android application is capable of multiplying the reputation of the restaurant as well as the customers with accelerated services.
\end{abstract}

KEYWORDS: Table Reservation, Android Application, Take away, Delivering of food, Restaurant management.

\section{INTRODUCTION}

This android application project allows the users to make a reservation of a table at a specific restaurant Along with flexibility of date and timeas Well as ordering the food instantly following by reservation of table, here the time where the person comes and takes the order will be saved and it also allows the user to order the food the home and also includes the option of take away by using their mobile phone or laptops from anywhere with the help of internet connectivity. This application also helps the admin (Restaurant manager) to edit the menu dynamically along with prices and have the overview of the table allotment according to the schedule and send the food to the particular table accordingly to the table by table number. It also includes the data analytics as well where the admin have clear view of the orders and admin can have the view of his orders from any corner irrespective of location.

\section{OBJECTIVE}

The main objective of this project is to give the restaurant management a software that is easy to manage the customers. This application also helps the customers to place the order from the home or work place to get the food delivered and also provides the option of take away the food from the restaurant itself. This android application is responsible for maintaining the waiters, menu items, pricing, payments and orders. The final objective is to bring all the classes of restaurants to a single platform for all the small end restaurants and to high- end restaurants. This application is useful in last minute planning.

\section{EXISTING SYSTEM}

In the existing system everything is to be done manually either by the waiters or the managers by pen-and-paper based operations which also leads to the wastage of paper as well as inks. Here in the existing system the table reservation has to be done either by contacting the restaurant at the reception or by walking to the hotel which leads to the wastage of time if the table are not available at the time of visit. The menus in the existing system are in the form of pen and paper based which again leads to the wastage of paper whenever the update is required even if small change is required. To manage all the stuff like accepting the table booking and 
rescheduling the table booking if required by the customer a person has to be allotted and to watch the payments and the taking the reviews and the billing counter as well which leads to much man power than required and also the salary for them and also we need to interact with the server or waiter for every small doubt or inquiry.so to conquer these problems we need to develop a platform which overcomes all the problems in keeping in mind all classes of the restaurant including low end and high end without any help of third party

\section{LITERATURE SURVEY}

In the prior years, There has been drastic improvements in the technology where we have got the online food ordering system from remote areas as well known as online food ordering application ${ }^{[1]}$.in the past years the mobile usage and the computing has also brought a lot of change in the technology and the smartphones have been upgrading day by day ${ }^{[2]}$.bringing a platform which provides food ordering was encouraged by the customers very much as well as the orders have been increasing day by day when compared to previous years. The another platform is made for the table reservation as well as the food ordering system simultaneously. Since the recent revolutionary trend has been made by the smartphones usage in which the android is an operating system. these platforms are helpful not only for the customers but they are useful for administrators to manage their management.

\section{PROPOSED SYSTEM}

In the proposed system we introduced the system of reserving a table at a specific date and time which is subjected to availability of tables in the restaurants along with ordering system at the time of booking itself. We also provide the customers to choose the from three different options which are Table Reservation, Order food and Take away options for the clients.For the admin we have options of table locking and unlocking table reservation for user for that particular restaurant. We have also introduced menu editing dynamically, pricing change, data analytics and total payments.

\section{SPECIFICATIONS}

Table reservation along with food ordering
Take away option: food can be picked at the restaurant.

Ordering food: ordering the food to home or local address.

\section{WORKFLOW}

\section{Admin:}

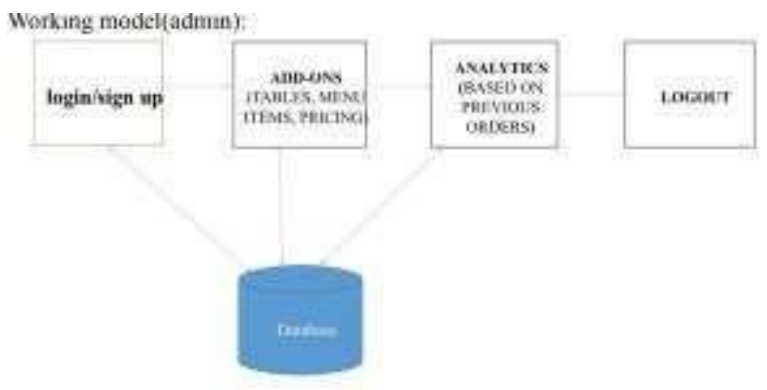

Customer:

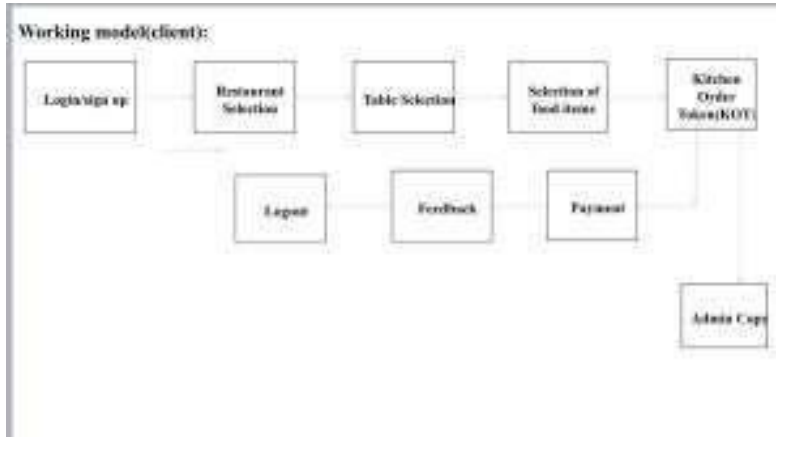

This figures represents the whole work flow process in the admin module and the client module

\section{RESULT}

In the project Customer enters the particular details to sign up get associated with app needed to be used in the Android App. The customer can have a look into the restaurants available and reserve a table or order the food.

This will let the customer to reserve a table and the reservation details are sent to the email ID or phone number of the user. The results and output screens are shown in the following Figures 

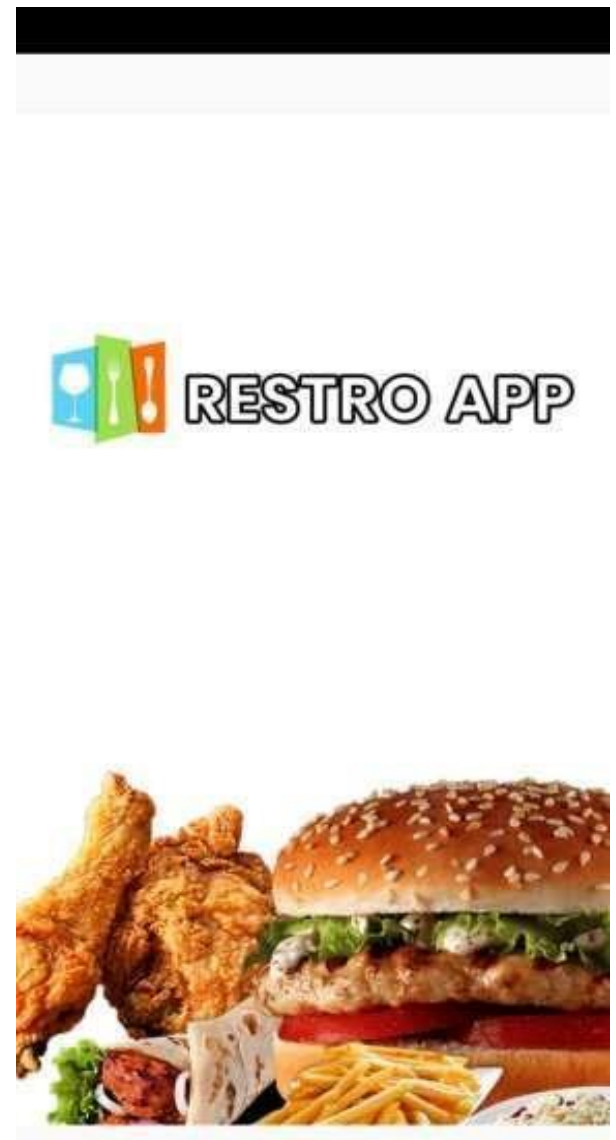

LOGIN/SIGN

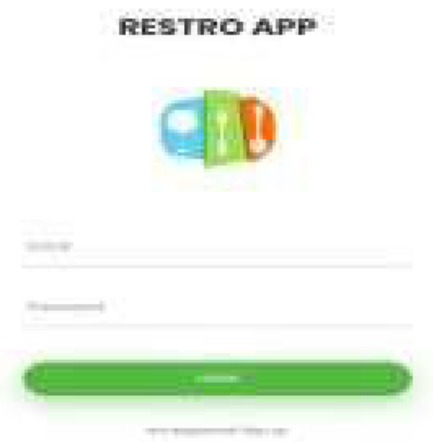

LIST OF RESTAURANTS
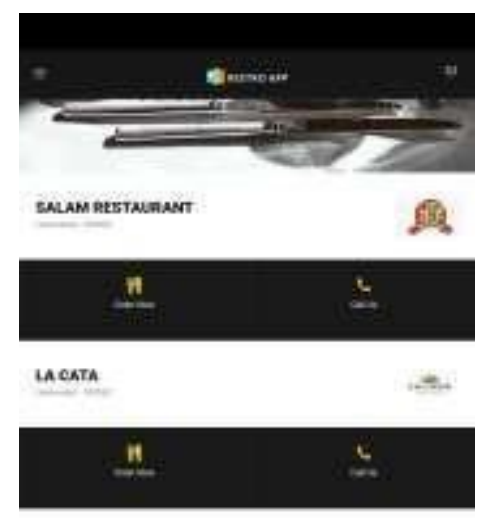

mapproes
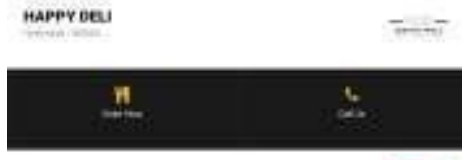

THE MoeoLe Bas
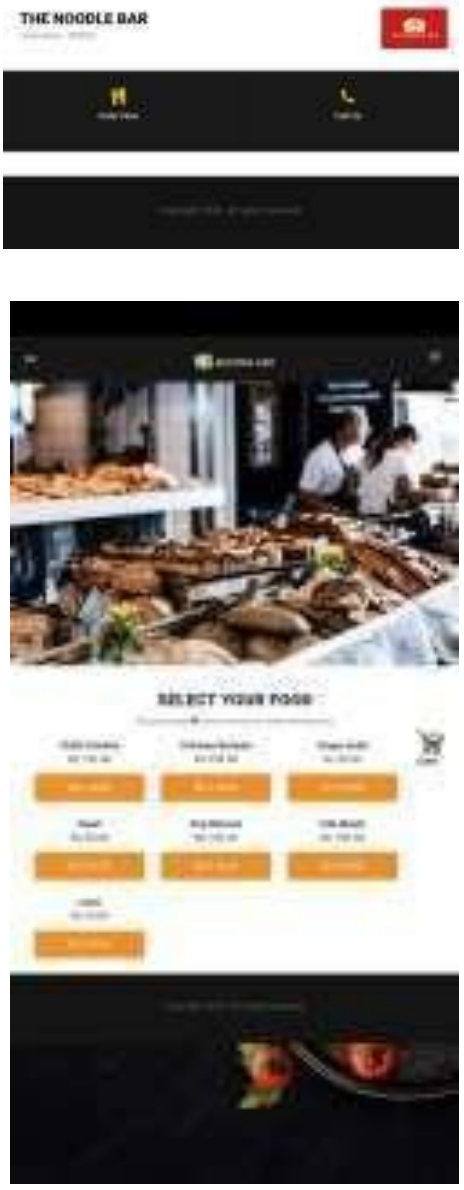

MENU 

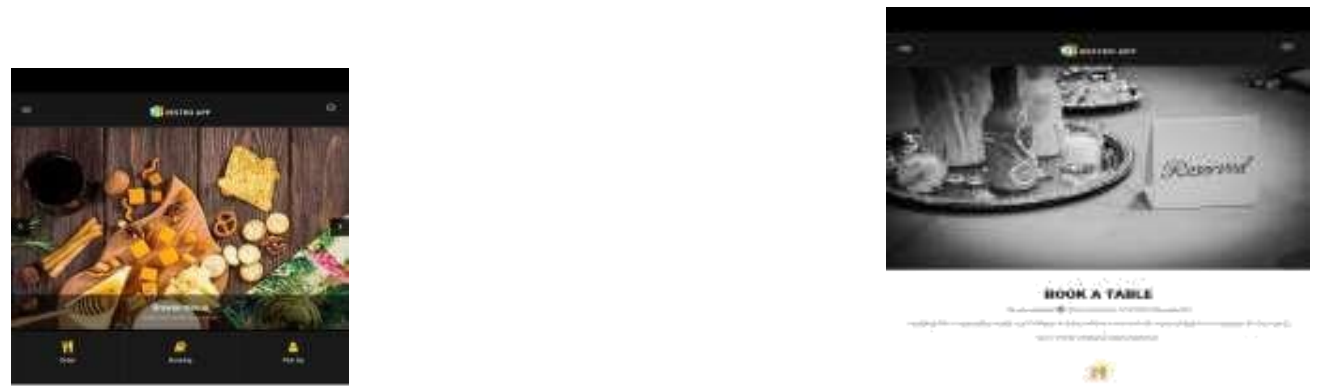

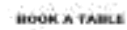

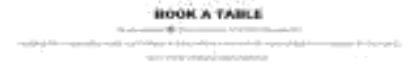

\{ำ.

"weiconeserwiv
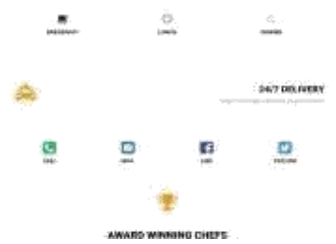

HOME PAGE

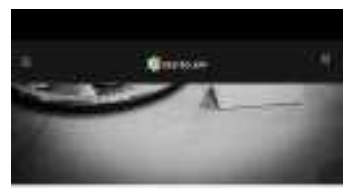

sockstane

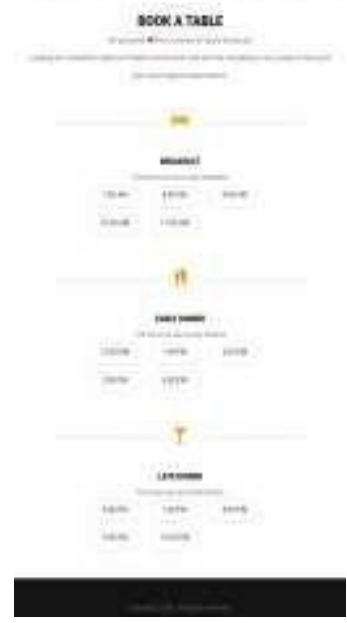

TABLE BOOKING PAGE

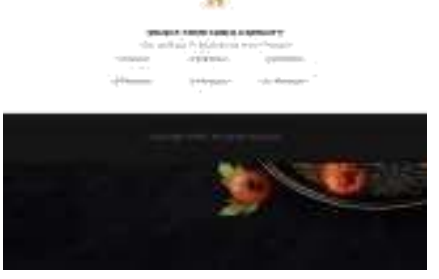

NO. OF PERSON SELECTION

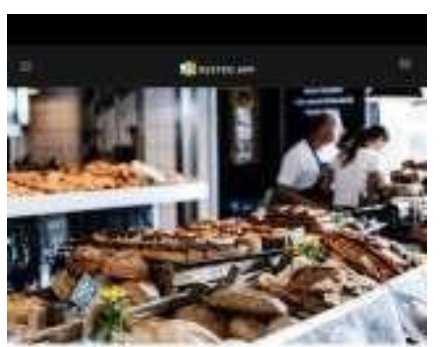

stLot Yous Peod

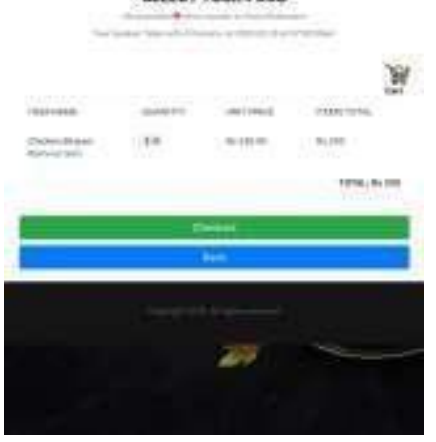

MENU SELECTION 


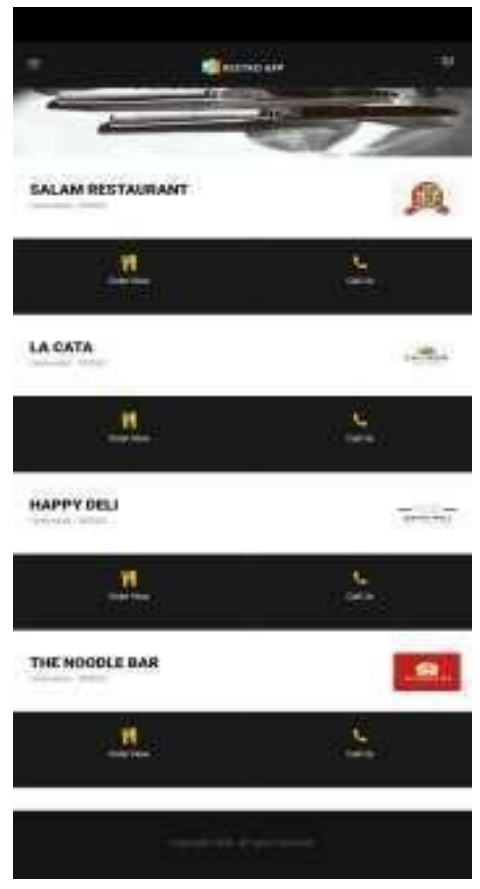

\section{CHECK OUT}

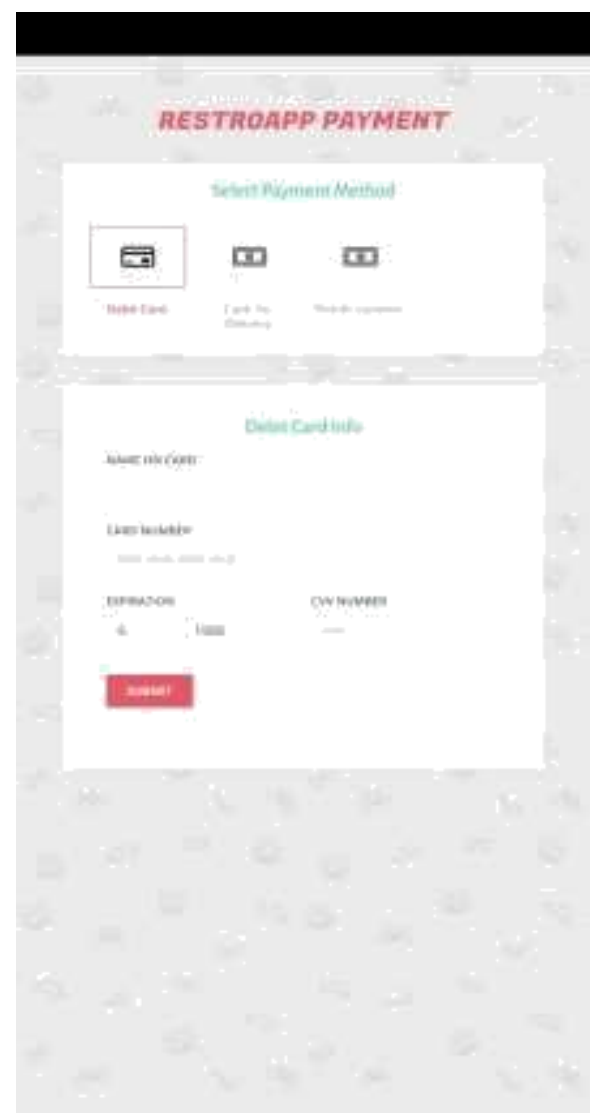

PAYMENT OPTIONS

\section{CONCLUSION}

To conclude that this restaurant management android application is implemented to reduce the manual process for both customer and management of the restaurant and to make the work look professionally. The manual system which were used in the past are do not serve the customer in the best possible way and the data can be edited but the new proposed application will have correct records of data and have no authority to edit or manipulate the data.

\section{REFERENCES}

[1] Paresh.R.Bora, Eshan Gupta, October (2012), "Application on Order Management Systems in Restaurant, "International Journal of Application or Innovation in Engineering \& Management (IJAIEM).

[2]S. R. Patil, Snehal Salunkhe, Nikita Kulkarni \& Priyanka Savant,

"E-converse An Affordable Touch

Screen Solution To Intrigue Dining Experience", Department Of Computer, Bharati Vidyapeeth's College Of Engineering.

[3] T.P. Liang, Chen Wei Huang, Y-HsuanYeh, Binshan Lin(2007). "Adoption of mobile technology in business- a fitviability model" Industrial Management \& data systems, vol . 107, pp. 1154-1169, 2007.

[4]DhoreB.,SurabhiThakar1,PrajaktaKulkarni, RasikaThorat(2014),

"Digital Table Booking and Food Ordering System Using Android

Application" in International Journal of Emerging Engineering Research and Technology Volume 2, Issue 7, October , PP 76-81.

[5]Shweta Shashikant Tanpure, Priyanka R.Shidankar, Madhura M. Joshi (2013),

"Automated Food Ordering System with RealTime Customer Feedback", in International Journal of Advanced Research in Computer Science and Software Engineering, Vol. 3, Issue 2, February 2013.

[6] Jhabuawala Mustafa, Kothari Radhika, NaikRiddhi,SlatewalaAbdulquadir(2012),

"Touch \& Dine-AMultiTouchable Restaurant System" in UACEE International Journal of Computer Science and its Applications - Volume 2: Issue 1. 
[7]Khairunnisa K.,Ayob J., Mohd.

HelmyA.Wahab, M. ErdiAyob, M. IzwanAyob, M. AfifAyob (2009),

"The Application of Wireless Food Ordering System", in MASAUM Journal of Computing, Volume 1 Issue 2, September.

[8] Soon Nyean Cheong, Wei Wing Chiew,Wen JiunYap(2010),

"Design and Development of MultiTouchable E-Restaurant Management System" ,in 2010 International Conference on Science and Social Research (CSSR 2010), December 5 - 7, 2010, Kuala Lumpur, Malaysia.

[9] Hanisah Binti Md Taha,(2008),

$$
\text { "Online Restaurant Management }
$$

System (ORMS),"Faculty of information and communication technology, Universitite knikal Malaysia melaka. 34.

[10]Mayur D. Jakhete , Piyush C.Mankar(2015),

"Implementation of

SmartRestaurant with e-menu Card" ,in

International Journal of Computer Applications (0975

- 8887) Volume 119 -No.21, June 2015. 